\title{
Comments on the Case for a Degree in Occupational Therapy
}

\author{
Douglas BenNett, 187 Woodstock Road, Oxford
}

Occupational therapy is rarely featured in psychiatric journals and little discussion takes place between our two professions. Now, however, we have a chance to consider a paper, issued by the Education Board of the College of Occupational Therapy, stating their case for a professional degree.

The Board believes that occupational therapists need a higher level of education and training if they are to match up to the changing requirements of their work and the demands for improvement in the quality of service which they offer to their and our patients. Developments in medical care mean that the professionals have to meet new demands. Such changes will almost certainly continue. It follows that instruction based on traditional knowledge, which is one of the characteristics of a vocational training, will never keep pace with that change and will always be out of date. In future, all practitioners, including occupational therapists, need to be educated to appreciate the many facets of a patient's difficulties, to be able to select relevant aspects for detailed attention and then apply their particular skills appropriately.

Such experience as one has had in working with graduate occupational therapists from Australia and North America, seems to confirm the Education Board's belief that higher education could lead to significant improvements in occupational therapy practice.

Making its case for a Degree Course, the Education Board quotes long passages from the Quirk Report on Education for Speech Therapists which was published in 1972: speech therapy being the only profession supplementary to medicine which requires a degree for admission. The paper goes on to compare the education of occupational therapists not only with that of speech therapists but with the education of teachers, social workers, physiotherapists and nurses, as well as occupational therapists in North America, Australia and South Africa. It regrets that no degree entry to the profession is available at present in this country. The Board further argues that if occupational therapy is to recruit its fair share of the available 18-yearolds with five ' $O$ ' and two ' $A$ ' Levels, it must be able to offer the cachet of a degree.

The paper then deals with the practical implementation of such a scheme. It states that the long-term aim is to provide for an 'all graduate' profession, since it believes that diploma training will not sustain the competence of an occupational therapist throughout her career. This hardly seems to be a practical aim if one considers the short duration of many occupational therapists' careers. More practical is the suggestion that pilot degree courses should be established in different institutions and structured in different ways, in order to discover the best approach. Another interesting suggestion is that graduates with an appropriate degree-for example, in psychology - could be trained as occupational therapists, possibly in a two-year version of the present diploma course. This would introduce new members into the profession who had a critical approach to research, to professional evaluation and training. It is suggested, however, that once this adjustment had been achieved 'the aim should be to move to limiting access to State Registration to those following the approved degree course'; in fact, to establish an 'all graduate' profession.

In my view the paper fails to examine and analyse with sufficient rigour the possible outcomes of this change. Instead of considering its effect on the numbers of trained Occupational Therapists available, on the National Health Service or on the public reaction to the profession, it only contemplates ways of establishing an education base for a degree. Talk about forming links with universities and polytechnics seems rather hopeful when, in hard times, such educational bodies are preoccupied with self preservation. There seems to be more hope than reality too in the belief that when it becomes possible to obtain degrees designed for occupational therapy, 'more and more occupational therapists will stay within the profession'. It is not only impossible to substantiate this view, but in the very next paragraph, the paper admits that there is no detailed knowledge of the manpower of the profession as a whole or of the likely requirements of the employing bodies. This cannot reassure psychiatrists who have observed, since the introduction of the Chronic Sick and Disabled Act, a marked drift of occupational therapists from work in psychiatric hospitals to employment with local authorities.

In spite of these very obvious difficulties, the College's Council proposes that within the next two to three years, a quarter of the student intake should be taking a degree course. It also proposes post-registration degree courses for senior members of the profession who had no opportunity of taking a degree.

The report concludes that 'the case for a graduate entry to the profession is well made'. Well, the case has been made in part. We certainly need graduate occupational therapists who can undertake the critical and thoughtful analysis of the patient's needs, who can determine the nature of their professional contribution and who can develop the theory and practice of their profession. The case that a cachet of a degree will lead to the retention of practitioners within the profession has not been made. Nor have the effects of this change on a relatively small profession, already short of members, received adequate critical attention. From the practical point of view there must be a longish period of trial 
and error with pilot courses in different settings.

Looking at the detailed course proposals set out in the Appendices from the point of view of the psychiatrist, one is reassured to see that they maintain a fair balance between the time given to biological and psychological aspects of training. Additional periods are devoted to research methods, social influences on behaviour and the management and administration of health care.
In summary, I think that psychiatrists should welcome and support a degree course in occupational therapy. However, it should be introduced gradually after more study and after more serious thought has been given to the far-reaching implications of an 'all graduate' entry, not only for occupational therapists but for their patients and other professions.

\section{Teaching Psychiatry: Scientific Myth}

\section{ToM W ALMSLEY, Clinical Teacher, Southampton University Medical School}

On the whole, when psychiatrists get together in meetings or conferences, they have a fairly good idea of what they are talking about. Discussion flows in a more or less coherent way. Even if the topic involved is problematic-say, the diagnostic criteria for schizophrenia-there is a general sense of agreement about what is meant by the words 'diagnosis' and 'schizophrenia'; even if the meanings are fuzzy at the edges. In areas of psychiatry made complex by the number of variables involved, statistical methods help to clarify the information gleaned, so that in the assessment of, for example, social factors in mental disorder, some clarity of conclusion prevails.

Nevertheless, it seems almost trite and wearisome to point out that there are profound differences of view within our discipline concerning the most fundamental issues and concepts with which psychiatrists are involved. I am not referring here to the examples given above-schizophrenia and social stress-but to issues and concepts even closer to the heart of psychiatry. In a way, I am referring to the issue of psychiatry itself.

As one reads the later papers of Sir Aubrey Lewis, ' one is grasped by the erudition with which this great psychiatrist addressed himself to matters at once profound and everyday in their character. As he reviewed the concepts of anxiety, endogeny and exogeny, paranoia and psychogenesis, Lewis revealed a formidable repertoire of intellectual sources, a battery of cultural references. Gradually, a more dramatic theme eventuates. Could it be that these words did less than flag the way to psychiatric concepts? Could it be that the words were the concepts themselves? Fortunately, such questions are less likely to arise at a psychiatric meeting than at a philosophical one.

It is perhaps unfortunate that, in these later papers, Lewis did not take on the word 'psychiatry'; and it is strange that in his earlier lecture on Johann Christian Reil, ${ }^{2}$ he failed to stress that this great, but forgotten, German coined the term. Had he done so, Lewis would surely have indicated that, as Reil developed the concept of psychiatry between 1800 and 1810 , he indicated clearly that psychiatry was a method of medical treatment in which the doctor used his psyche as the primary therapeutic agent. The 'psyche' of psychiatry is the doctor's psyche, not the psyche of the patient. Certainly, such a usage of 'psychiatry' would render the word 'psychotherapy' redundant. It would have other, further reaching consequences also. The fact is that many psychiatrists do not comprehend the meaning of psychiatry as it was originally conceived.

Reil's invocation of the psyche to the process of medical treatment was both consonant and dissonant with the spirit of his times. Chiarugi in Italy, Tuke in the United Kingdom, Pinel in France and (perhaps) Rush in the United States of America were energetically pursuing novel methods of approach in the treatment of the mentally ill. However, while Tuke was content with the notion of 'moral' treatment, Reil, through his contacts with anti-rational, romantic, transcendental philosophy (especially as represented by Schelling), invoked a Goddess-Psyche. And, as Esquirol built on the original work of Pinel, so Heinroth refined and expanded the concepts of Reil. By choosing to use the term 'psyche', Reil and Heinroth involved their discipline with mythological modes of thought. Many psychiatrists believe that to associate their profession with the concept of 'myth' is insulting and derogatory. In fact, to characterize psychiatric matters as myths is to hit on a fundamental truth about the nature of myth.

The myth of Psyche and Eros with its details of their clandestine sexual relationship was finally spelt out by Apuleius. More recently, $\operatorname{Simon}^{3}$ has thrown light on the early history of the psyche. He provides quotations from Homer to show that the psyches live in a 'far away place' (not the underworld), they flit about like shadows, are 'unintelligent' and can speak only after drinking the blood of slain animals. Their substance is that of figures in dreams and they live near the 'village of dreams'.

In summary, Simon indicates psyche is not a faculty or agency of the self so much as a continuation of the whole person. Furthermore, as many writers have stated or suggested, the psyche carries the connotation of the 'double'. In this way, the mirror-as 'reflected' in the pool of Narcissus-assumes its profound psychic significance. Such 